\title{
A prospective study to evaluate the role of routine early third trimester ultrasound in the diagnosis of intrauterine growth restriction and prediction of adverse perinatal outcome using color Doppler
}

\author{
Shabd Singh Yadav', Aditi Singh²*, Kalpana Yadav ${ }^{2}$ \\ ${ }^{1}$ Department of Paediatrics, ${ }^{2}$ Department of Obstetrics and Gynecology, Shyam Shah Medical College, Rewa, Madhya \\ Pradesh, India
}

Received: 19 August 2020

Accepted: 29 September 2020

\author{
*Correspondence: \\ Dr. Aditi Singh, \\ E-mail: aditisingh128@gmail.com
}

Copyright: $\odot$ the author(s), publisher and licensee Medip Academy. This is an open-access article distributed under the terms of the Creative Commons Attribution Non-Commercial License, which permits unrestricted non-commercial use, distribution, and reproduction in any medium, provided the original work is properly cited.

\begin{abstract}
Background: Intrauterine growth restriction (IUGR) is a major and silent cause of perinatal morbidity and mortality. Rate of IUGR in developing countries is 6 times higher than that of developed countries. 14 to 20 million infants are affected with IUGR in developing countries annually. The highest incidence is found in south central Asia (33\%) and India $(21 \%)$. Aim of study was to evaluate the role of early 3rd trimester ultrasound in diagnosis and role of color Doppler in prediction of adverse perinatal outcome in IUGR.

Methods: A prospective case-control study was conducted on 720 women admitted in GMH Rewa for one year. 360 antenatal cases diagnosed as IUGR on ultrasound were taken as study group, same number of non IUGR cases were taken as control. Study cases were followed with Doppler. The umbilical artery pulsatility index (UA PI), middle cerebral artery pulsatility index (MCA PI) and cerebro-placental ratio were calculated and the results were analysed.

Results: Inferences drawn from the study were: rate of caesarean section was significantly higher (31\%) in study group, perinatal outcome was poor in more number of cases (10.8\%) in study group than the control group (3.4\%), and the sensitivity and specificity of cerebroplacental ratio was more reliable indicator in comparison to that of UA PI and MCA PI in prediction of adverse perinatal outcome.

Conclusions: Looking at the high burden of IUGR cases in our country and its adverse effects on perinatal outcome, if early third trimester ultrasound is made mandatory for all pregnant women, most of the IUGR cases can be detected and managed timely and perinatal outcome can be significantly improved.
\end{abstract}

Keywords: IUGR, Colour Doppler, Cerebroplacental ratio, Perinatal morbidity

\section{INTRODUCTION}

Intrauterine growth restriction (IUGR) is a multi-factorial condition which leads to significant fetal morbidity and mortality. Its importance was timely established when Battaglia and Lubchenco classified small-for-gestational age (SGA) neonates as those whose weights were below the 10th percentile for their gestational age. ${ }^{1}$

IUGR is defined as birth weight below the $10^{\text {th }}$ percentile of the recommended gender specific birth weight for gestational age reference curves by Williams and the World Health Organization (WHO). ${ }^{2}$ It is a major burden in developing countries attributing to 14 to 20 million infants being affected annually. The highest incidences are found in south central Asia (33\%), that too India accounts for $21 \%$ of cases in the world. ${ }^{3,4}$ The rate of IUGR in developing countries is about 6 times higher than that in developed countries.

Impairment in fetal growth has consequences in infancy and childhood in terms of mortality, morbidity, growth and 
performance. So screening for IUGR in a new-born is necessary for the diagnosis, management and prognosis. IUGR infants not only have higher association with congenital anomalies, they have long term neurological deficits. Also the Barker hypothesis states that IUGR is a major cause for the development of chronic diseases such as cardiovascular diseases, stroke, hypertension, type-2 diabetes and obesity later in life. ${ }^{5}$ A modern classification system of stillbirth, Recode, has shown that IUGR is the most common factor identified in stillborn babies $(43 \%){ }^{6}$

Timely diagnosis of IUGR is a challenge which was earlier solely based on serial physical examinations such as maternal weight charting, abdominal girth and fundal height charting. Later with the advent of sonography, serial biometry became the significant tool.

The advent of color Doppler has enabled more precise examination of the uteroplacental and fetoplacental circulation.

Timely diagnosis and management of IUGR is one of the major achievements in contemporary obstetrics. If the growth-restricted fetus is identified and appropriate management instituted, perinatal mortality and morbidity can be reduced, underscoring the need for assessment of fetal growth at each prenatal visit.

This study was conducted with the aim of improving the diagnostic, preventive and curative facilities for the healthiest outcome of neonates in our institute.

\section{METHODS}

The study protocol was approved by the Institute's ethics committee. All subjects were included in the study after an informed written consent. Participation in the study was voluntary.

This prospective study was conducted on 720 antenatal patients admitted in Gandhi Memorial Hospital, associated with Shyam Shah Medical College and Hospital, Rewa (Madhya Pradesh) for a period of one year from 01 July 2016 to 30 June 2017.

\section{Inclusion criteria}

Patients with antenatal cases with gestational age between 28-36 weeks. Singleton pregnancy, patients attending antenatal outpatient department (OPD), admitted in antenatal ward and labour room, were included in this study.

\section{Exclusion criteria}

Patients in labour, patients with mistaken dates, patients with intrauterine fetal demise, were excluded from this study.
Detailed history was obtained. Gestational age was carefully determined, in cases with mistaken dates help of first trimester ultrasound was taken. A general and relevant systemic examination performed followed by a thorough obstetric examination to know gestational age, lie, presentation, amount of liquor, baby weight, fetal wellbeing, symphysio-fundal height, and abdominal girth. All routine blood and urine examination were done.

Routine ultrasound was done to measure biparietal diameter (BPD), head circumference (HC), abdominal circumference (AC), femur length (FL), estimated fetal weight $(\mathrm{EFW})$, amniotic fluid index (AFI) and placental changes. On the basis ultrasound patients were divided into cases i.e. with IUGR and control i.e. non-IUGR. IUGR cases were followed with Doppler studies. All the patients were followed till delivery and neonatal birth weight, ponderal index and perinatal outcome were noted.

The data were entered into Microsoft excel spread sheet and analyzed. Frequency and present values were computed for qualitative variables. Mean values were compared using analysis of variance. Frequency distributions were compared using Chi-square/Fisher's exact test as appropriate. Sensitivity and specificity analyses were done for comparing umbilical artery (UA) and middle cerebral artery (MCA) Doppler indices and cerebroplacental ratio was calculated.

\section{RESULTS}

Total 720 antenatal women who fulfilled the inclusion and exclusion criteria with consent were studied. They were divided into study group $(\mathrm{N}=360)$ with IUGR on sonography and control group $(\mathrm{N}=360)$ without IUGR.

\section{Demographics}

Maximum number of cases were between 20-29 years age group in study $(87.8 \%)$, as well as in control group $(92.7 \%)$. In age group $>35$ years incidence of IUGR was highest i.e. $75 \%$. Most of cases were un-booked in both study $(83.9 \%)$ and control group (73.3\%). Out of all the un-booked cases, $53.35 \%$ were found to be having IUGR $(\mathrm{p}=0.0008)$.

IUGR was more common in illiterate cases (52.4\%). Among labourers, $59.63 \%$ women were found to be having IUGR foetuses $(\mathrm{p}=0.0175)$.

Incidence of IUGR was higher in lower socioeconomic status $(54.21 \%)(\mathrm{p}=0.0139)$.

Among underweight women, $63.63 \%$ were found to be having IUGR. Similarly among obese women, $61.53 \%$ were having IUGR. Incidence of IUGR was highest in grand multipara $(63.63 \%)$.

The study shows that majority of women are primigravida in both study $(54.44 \%)$ and control group (62.2\%). 
Incidence of IUGR was higher in grand multipara $(63.63 \%)$.

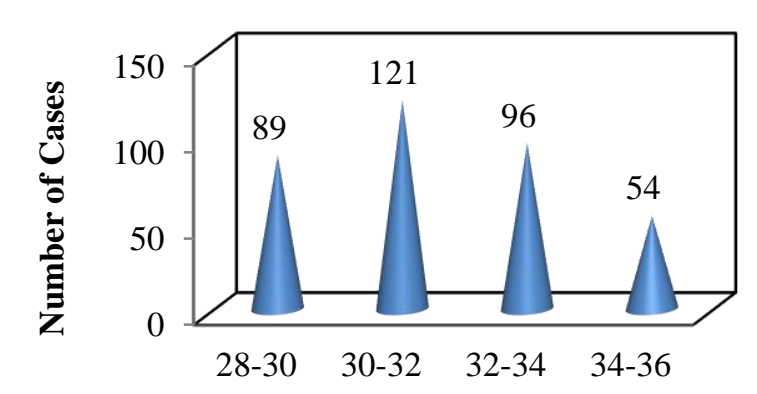

Gestational age (weeks)

- Study Group (n=360)

Figure 1: Distribution of cases according to gestational age.

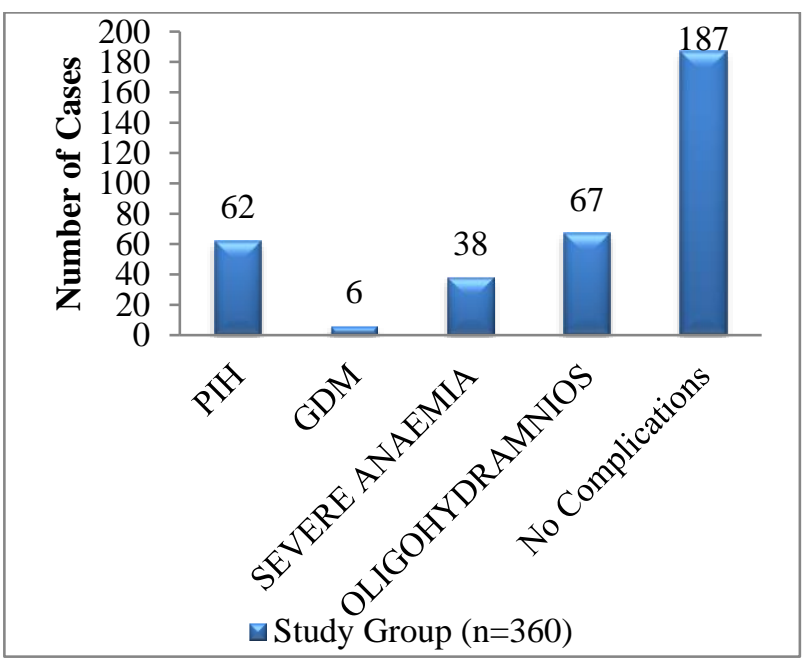

\section{Figure 2: Distribution of cases according to maternal} complications.

In study group, out of 360 cases, $48.1 \%$ of women had some maternal complications. Incidence of IUGR was $71.2 \%, 60 \%, 77.5 \%$ and $80.72 \%$ in cases of pregnancyinduced hypertension (PIH), gestational diabetes mellitus (GDM), severe anaemia and oligohydramnios respectively.

Most of the cases in the study as well as control group were delivered at term gestational age (GA) (>37 weeks) i.e. $80.6 \%$ and $91.9 \%$ respectively.

Incidence of preterm delivery was higher in study group which was $19.4 \%$.

Incidence of stillbirth, intrauterine device (IUD), early neonatal death and late neonatal death was more in study group $(1.6 \%, 1.1 \%, 5.3 \%$ and $0.83 \%)$ as compared to control group $(0.27 \%, 0.5 \%, 1.66 \%$ and $0.27 \%)$ respectively.

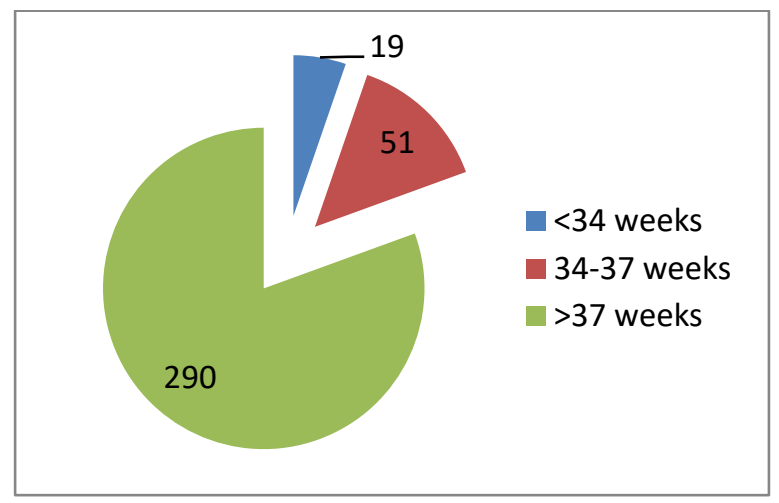

Figure 3: Gestational age at delivery in the study group

Majority of women had term vaginal delivery in both study $(58.05 \%)$ and control group $(83.9 \%)$. Percentage of caesarean was higher in the study group (31.7\%) as compared to the control group (11.1\%).

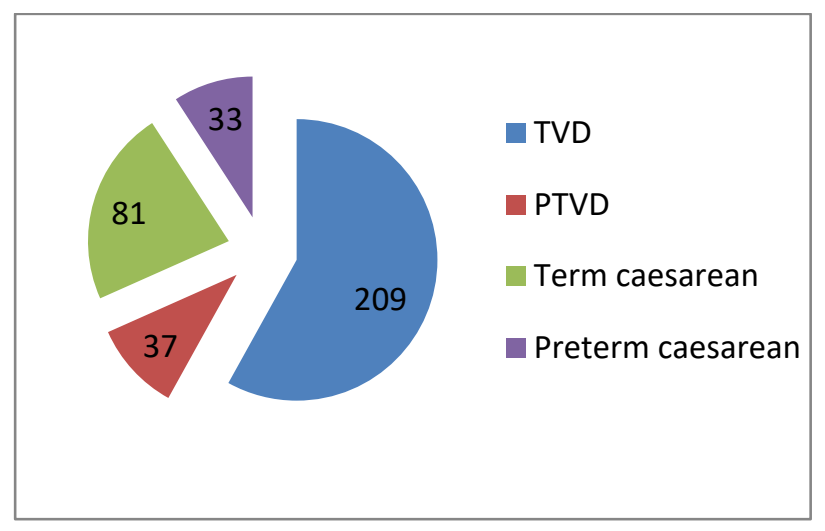

Figure 4: Mode of delivery in the study group.

Maximum babies had birth weight between $2-2.5 \mathrm{~kg}$ in study (54.44\%) and $2.5-3 \mathrm{~kg}$ in control group (55.3\%).

Incidence of birth weight below $2 \mathrm{~kg}$ was $15.83 \%$ in study group and $4.4 \%$ in control group.

$14.72 \%$ of babies in study group were admitted in neonatal intensive care unit (NICU) for less than seven days and $7.5 \%$ were admitted for longer.

\section{Biometry}

In study group abdominal circumference (AC) was the most reliable indicator for diagnosing IUGR i.e. in $91.1 \%$ of study cases AC was below 10th centile. Head circumference (HC) and femur length (FL) were found to be less than 10th centile in $10.8 \%$ and $3.3 \%$ of cases respectively. 


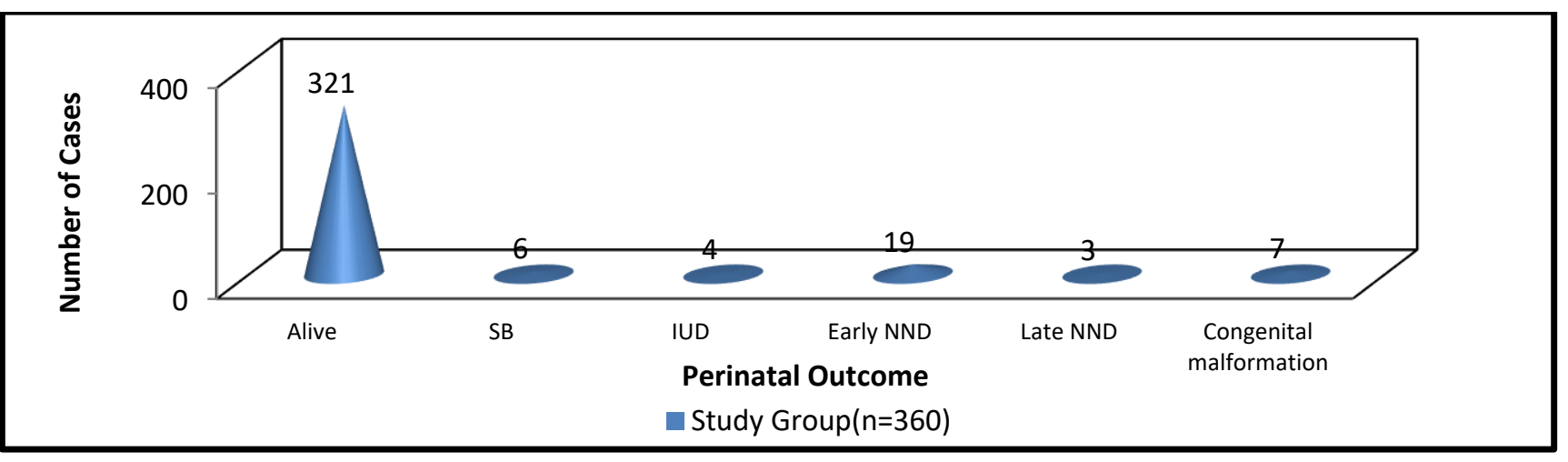

Figure 5: Distribution of cases according to perinatal outcome.

Table 1: Distribution of cases according to perinatal complications.

\begin{tabular}{|c|c|c|c|c|}
\hline \multirow{2}{*}{ Perinatal complications } & \multicolumn{2}{|c|}{ Study group ( $\mathbf{N = 3 6 0 )}$} & \multicolumn{2}{|c|}{ Control group $(\mathrm{N}=\mathbf{3 6 0})$} \\
\hline & $\mathbf{N}$ & $\%$ & $\mathbf{N}$ & $\%$ \\
\hline Respiratory distress syndrome & 26 & 7.2 & 7 & 1.9 \\
\hline Meconium aspiration syndrome & 8 & 2.2 & 2 & 0.5 \\
\hline Hypoglycemia & 4 & 1.1 & 1 & 0.27 \\
\hline Hypothermia & 3 & 0.83 & 1 & 0.27 \\
\hline Hyperbilirubinimia & 7 & 1.9 & 2 & 0.5 \\
\hline Hypocalcaemia & 2 & 0.5 & 0 & 0 \\
\hline Haematological complications & 6 & 1.6 & 2 & 0.5 \\
\hline Necrotizing enterocolitis & 3 & 0.83 & 1 & 0.27 \\
\hline Septicemia & 2 & 0.5 & 1 & 0.27 \\
\hline No complication & 299 & 83.05 & 343 & 95.27 \\
\hline Total & 360 & 100 & 360 & 100 \\
\hline
\end{tabular}

$\mathrm{X}^{2}=28.466, \mathrm{p}=0.0008$, significant

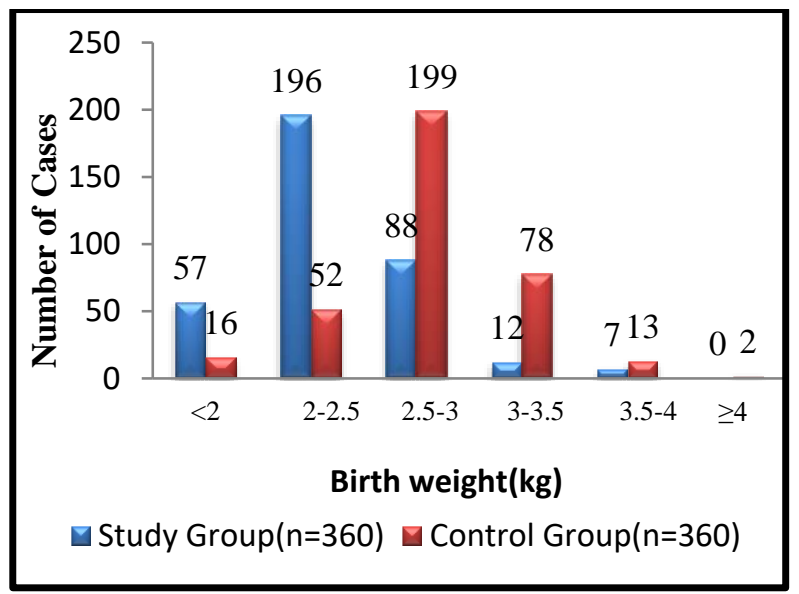

Figure 6: Distribution of cases according to birth weight.

$\mathrm{HC} / \mathrm{AC}$ ratio was $>1$ in $64.7 \%$ of cases making most of the cases asymmetrical IUGR.

Among study group, $14.4 \%$ had amniotic fluid index (AFI) $<5$ suggesting oligohydramnios. In control group only $4.4 \%$ had AFI <5. Incidence of IUGR in oligohydramnios is $76.47 \%$.

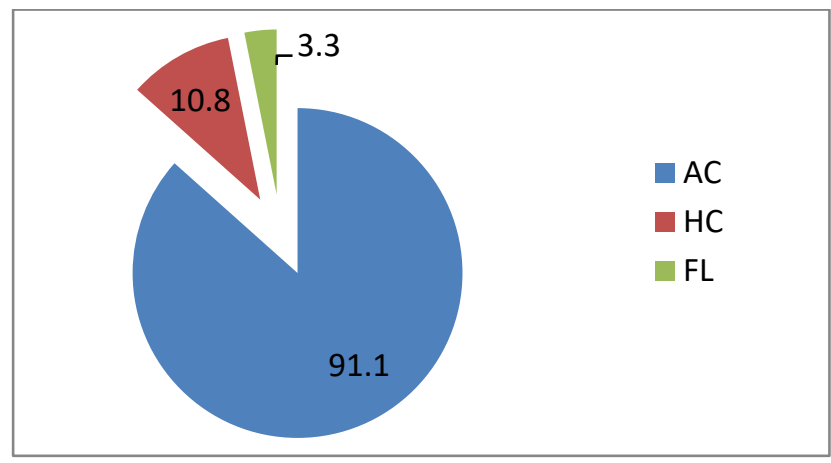

Figure 7: USG parameter below 10th centile.

Table 2: Distribution of cases according to $3^{\text {rd }}$ trimester USG AFI.

\begin{tabular}{|lllll|}
\hline \multirow{2}{*}{ AFI } & \multicolumn{2}{l}{$\begin{array}{l}\text { Study group } \\
(\mathbf{N = 3 6 0 )}\end{array}$} & \multicolumn{2}{l|}{$\begin{array}{l}\text { Control group } \\
(\mathbf{N}=360)\end{array}$} \\
\cline { 2 - 5 } & $\mathbf{N}$ & $\mathbf{\%}$ & $\mathbf{N}$ & $\mathbf{\%}$ \\
\hline$<\mathbf{5}$ (oligo) & 52 & 14.4 & 16 & 4.4 \\
\hline$>\mathbf{5}$ & 303 & 84.1 & 341 & 94.7 \\
\hline$>\mathbf{2 5}$ (poly) & 5 & 1.3 & 3 & 0.8 \\
\hline Total & 360 & 100 & 360 & 100 \\
\hline
\end{tabular}




\section{Doppler indices}

Table 3: Evaluation of umbilical artery PI in prediction of perinatal outcome.

\begin{tabular}{|llll|}
\hline UA PI & Admitted & $\begin{array}{l}\text { Not } \\
\text { admitted }\end{array}$ & Total \\
\hline $\begin{array}{l}\text { Abnormal PI } \\
\left(>95^{\text {th }} \text { percentile) }\right.\end{array}$ & 68 & 35 & 103 \\
\hline Normal PI & 12 & 245 & 257 \\
\hline Total & 80 & 280 & 360 \\
\hline
\end{tabular}

Sensitivity of umbilical arterial pulsatility index (UA PI)$85.71 \%$, specificity- $87.6 \%$, predictive value of a positive test$66.01 \%$, predictive value of a negative test- $95.3 \%$

Table 4: Evaluation of MCA PI in prediction of perinatal outcome.

\begin{tabular}{|llll|}
\hline MCA PI & Admitted & $\begin{array}{c}\text { Not } \\
\text { admitted }\end{array}$ & Total \\
\hline $\begin{array}{l}\text { Abnormal PI } \\
\left(<\mathbf{5}^{\text {th }} \text { percentile }\right)\end{array}$ & 56 & 51 & 107 \\
\hline Normal PI & 24 & 229 & 253 \\
\hline Total & 80 & 280 & 360 \\
\hline
\end{tabular}

Sensitivity of middle cerebral artery pulsatility index (MCA PI)$70 \%$, specificity- $81.8 \%$, predictive value of a positive test$52.33 \%$, predictive value of a negative test- $90.51 \%$

Table 5: Evaluation of cerebro-placental ratio in prediction of perinatal outcome.

\begin{tabular}{|llll|}
\hline CPR & Admitted & $\begin{array}{l}\text { Not } \\
\text { admitted }\end{array}$ & Total \\
\hline $\begin{array}{l}\text { Abnormal } \\
(<\mathbf{1} \text { percentile })\end{array}$ & 72 & 30 & 102 \\
\hline Normal $(>\mathbf{1})$ & 8 & 250 & 258 \\
\hline Total & 80 & 280 & 360 \\
\hline
\end{tabular}

Sensitivity of cerebro-placental ratio (CPR)- $90.1 \%$, specificity$89.9 \%$, predictive value of a positive test- $70.6 \%$, predictive value of a negative test- $96.8 \%$

\section{DISCUSSION}

The demographic factors in our study were similar to those in other studies like IUGR was common with extremes of age, women with lower socioeconomic status, who were unbooked, with poor literacy levels, belonging to rural areas and in women with heavy physical work. Similar results were found in the studies done by Lean et al, Ravikumar et al, Odibo et al and Kramer's meta-analysis. ${ }^{7-}$ 10

Incidence of IUGR was highest among women with body mass index (BMI) $<18.5$ i.e. $63.3 \%$ showing that IUGR is common among women with poor nutritional status. This is similar in the study done by Acharya et al and Kramer's meta-analysis. ${ }^{10,11}$

Incidence of IUGR was very high with associated maternal complications such as PIH, GDM, severe anaemia and oligohydramnios. The main reason is the compromised utero-placental circulation in these conditions. This was consistent with studies done by Bassetty et al and Morris et al. ${ }^{12,13}$

Number of early and late pre-term deliveries was higher in the study group. The incidence of caesarean section was also higher in the IUGR cases $(31.7 \%)$ as compared to the control group (11\%). This was similar to the study done by Ryan et al. ${ }^{14}$

Perinatal outcome was poorer in the IUGR babies as evident by increased still births, IUDs, early and late neonatal deaths and congential malformations. It was observed that respiratory distress was a major confounding factor in causing early neonatal deaths. Unterscheider et al conducted the prospective observational trial to optimise paediatric health in IUGR (PORTO) on 1,200 singleton pregnancies and found that fetal growth restriction is the single most important contributor to perinatal mortality in non-anomalous foetuses. ${ }^{15}$ The rate of NICU admission was also higher in the IUGR cases which is similar to result found by Sharma et al. ${ }^{16}$

On routine third trimester ultrasound 360 women ultrasound were found with IUGR. AC was the single most parameter abnormal in most of the cases i.e. in $91.1 \%$. It is similar to the studies done by Larciprete et al and Baschat et al. ${ }^{17,18}$

In our study, 150 cases were at more than 32 weeks of gestation. Out of these cases $64.7 \%$ had $\mathrm{HC} / \mathrm{AC}$ ratio below one making them cases of asymmetrical IUGR. In a study by Vandenbosche et al. An HC/AC ratio of greater than one detects about 85 percent of growth-restricted foetuses. ${ }^{19}$ The percentage of IUGR in cases with oligohydramnios is very high indicating its close association with the condition similar to study done by Morris et al. ${ }^{13}$

All the cases diagnosed as IUGR on examination and ultrasound biometry were studied with color Doppler and followed for the perinatal outcome, which included NICU admissions, IUD, still births, early and late neonatal deaths.

The S/D ratio, PI and resistive index (RI) of UA and MCA were studied with respect to the perinatal outcome. We deduced that sensitivity, specificity, positive predictive and negative predictive value of UA PI were greater than MCA PI, making it a better diagnostic indicator. This was consistent with result of the study done by Khanduri et al on 60 antenatal women, where he found that the PI of the umbilical artery was more sensitive than the PI of the middle cerebral artery. ${ }^{20}$ UA PI has the maximum overall diagnostic accuracy of $75 \%$. Same result was obtained by a study done by Malik et al. ${ }^{21}$

The CPR is calculated by dividing the Doppler indices of the MCA by the UA and represents the interaction of 
alterations in blood flow to the brain as manifest by increased diastolic flow as the result of cerebrovascular dilation resulting from hypoxia and increased placental resistance, resulting in decreased diastolic flow of the UA.

In our study sensitivity, specificity, positive and negative predictive value of CPR was the highest making it a very important diagnostic and prognostic indicator. Similar results were observed by Ray and Singh et al, Gandhi et al and DeVore. ${ }^{22-24}$

\section{CONCLUSION}

Majority of the cases of IUGR can be detected on an early routine third trimester ultrasound and growth of the foetus can be followed on serial ultrasound. Further if we study the placento-fetal circulation by the various Doppler indices, any stress on the foetus can be determined timely and we can plan the time and mode of delivery to give the best possible perinatal outcome.

\section{ACKNOWLEDGMENTS}

Authors would like to thank Dr. Nirupam, Dr. Khanna for his support during study.

Funding: No funding sources Conflict of interest: None declared

Ethical approval: The study was approved by the Institutional Ethics Committee

\section{REFERENCES}

1. Battalglia FC, Lubchenco LO. A practical classification of new born infants by weight and gestational age. J Paediatr.1967;71(2):159-63.

2. World Health Organization. Expert Committee Report: Physical status: the use and interpretation of anthropometry. Technical Report Series 854. Geneva: World Health Organization. 1995.

3. De Onis M, Blössner M, Villar J. Levels and patterns of intrauterine growth retardation in developing countries. Eur J Clini Nutr.1998;52(1):5-15.

4. Director General World Health Organization. Bridging the gaps. The World Health Report. 1995.

5. Barker DJ, Osmond C, Golding J, Kuh D, Wadsworth ME. Growth in utero, blood pressure in childhood and adult life, and mortality from cardiovascular disease. BMJ. 1989;298(6673):564-7.

6. Gardosi J, Kady SM, McGeown P, Francis A, Tonks A. Classification of stillbirth by relevant condition at death (ReCoDe): population based cohort study. BMJ. 2005;331:1113.

7. Lean SC, Heazell AEP, Dilworth MR, Mills TA, Jones RL. Placental Dysfunction Underlies Increased Risk of Fetal Growth Restriction and Stillbirth in Advanced Maternal Age Women. Sci Rep. 2017;7(1):9677.
8. Ravikumar K, Rajeshkannan B. A Descriptive Study of Maternal Risk Factors in Term Babies with IUGR. J Dent Med Sci. 2016;15(12):48-51.

9. Odibo AO, Nelson D, Stamilio DM, Sehdev HM, Macones GA. Advanced maternal age (AMA) is an independent risk factor for intrauterine growth restriction (IUGR). Am J Perinatol. 2006;23(5):3258.

10. Kramer MS. Determinants of low birth weight: Methodological assessment and meta-analysis. Bull World Health Organiz.1987;65:663-737.

11. Acharya D, Nagraj K, Nair NS, Bhat HV. Maternal determinants of intrauterine growth retardation: a case control study in Udupi district, Karnataka. Ind $\mathbf{J}$ Comm Med. 2004;29(4):10-2.

12. Bassetty KC, Phukan P, Ahmed RD, Borah R. Outcomes of Neonates in Pregnancies with Intrauterine Growth Restriction in Developing Countries: A Cross-sectional Study Over a Period of 6 Months. Gynecol Obstet 2017;7:434.

13. Morris RK, Meller CH, Tamblyn J, Malin GM, Riley RD, Kilby MD, et al. Association and prediction of amniotic fluid measurements for adverse pregnancy outcome: Systematic review and meta-analysis. BJOG. 2014;121(6):686-99.

14. Ryan D, Black MJ. Preterm Birth and or Factors that Lead to Preterm Delivery: Effects on the Neonatal Kidney. J Neonatal Biol. 2015;4:168.

15. Unterscheider J, Daly S, Geary MP. Optimizing the definition of intrauterine growth restriction: the multicenter prospective PORTO Study. Am J Obstet Gynecol. 2013;208(4):2901-6.

16. Sharma D, Shastri S, Farahbakhsh N, Sharma P. J Matern Fetal Neonatal Med. 2016; 29(24):3977-87.

17. Larciprete G, Valensise H, Di Pierro G, Vasapollo B, Casalino B, Arduini D, Jarvis S, Cirese E. Intrauterine growth restriction and fetal body composition. Ultrasound Obstet Gynecol. 2005;26:258-62.

18. Baschat AA, Weiner CP. Umbilical artery Doppler screening for detection of the small fetus in need of antepartum surveillance. Am J Obstet Gynecol. 2000; $182: 154-8$.

19. Vandenbosche RC, Kirchner JT. Intrauterine growth retardation. Am Fam Physician. 1998;58(6):1384-90.

20. Khanduri S, Parashari UC, Bashir S, Bhadury S, Bansal A. Comparison of Diagnostic Efficacy of Umbilical Artery and Middle Cerebral Artery Waveform with Color Doppler Study for Detection of Intrauterine Growth Restriction. J Obstet Gynaecol India. 2013;63(4):249-55.

21. Malik R, Saxena A. Role of Colour Doppler Indices in the Diagnosis of Intrauterine Growth Retardation in High-Risk Pregnancies. J Obstet Gynaecol India. 2013;63(1):37-44.

22. Bahado-Singh RO, Kovanci E, Jeffres A, Oz U, Deren O, Copel J, Mari G. The Doppler cerebroplacental ratio and perinatal outcome in intrauterine growth restriction. Am J Obstet Gynecol. 1999;180(3 Pt 1):750-6. 
23. Gandhi K, Mehta AV. Role of Doppler Velocimetry in growth restricted foetuses. NHL J Med Sci. 2015;4(1):27-30.

24. De Vore GR. The importance of the cerebroplacental ratio in the evaluation of fetal well-being in SGA and AGA foetuses. Am J Obstet Gynecol. 2015;213(1):515.
Cite this article as: Yadav SS, Singh A, Yadav K. A prospective study to evaluate the role of routine early third trimester ultrasound in the diagnosis of intrauterine growth restriction and prediction of adverse perinatal outcome using color Doppler. Int J Reprod Contracept Obstet Gynecol 2020;9:4506-12. 